\title{
The Correlates of Violence against Women and Surveillance of Novel Coronavirus (COVID -19) Pandemic Outbreak Globally: A Systematic Review and Meta-Analysis
}

\author{
Eyayu Kasseye Bayu \\ Department of Gender and Development Studies, College of Social Science and Humanities, University of \\ Gondar, Ethiopia
}

\begin{abstract}
Background: COVID-19 is a serious global pandemic with more than 1 million confirmed cases and 64,000 deaths. Cases of coronavirus disease 2019 (COVID-19) are rapidly increasing and infected millions globally. Violence against women and girls is also a global human rights violation and public health problem in lockdown period.

Methods: A systematic review of studies were conducted to show the relationship between impacts of COVID-19 and violence against women, and their impacts on women's health and human rights globally. The systematic selection of case reports, clinical trials, health institutions guidelines (e.g. WHO, CDC), review reports by experts, commentators reports, editor's letters, and available indexed articles/journals were undertaken. The author conducted the literature search on March 20 up to 02 May2020, where existing quantitative and qualitative data are included in this review.

Results: COVID-19 is a serious global pandemic with more than 1 million confirmed cases and 64,000 deaths. The COVID-19 pandemic has been the fastest-moving global public health crisis in a century, causing significant mortality and morbidity and giving rise to daunting health and human rights violations. As the findings demonstrate, there is an increase of violence during the period of lockdown. As a result of COVID-19, violence against women can result in injuries and serious physical, economical, mental, sexual and reproductive health problems, including sexually transmitted infections, HIV, and unplanned pregnancies in lockdown. Hence, the health and human rights of women generally is adversely impacted globally due to COVID-19.

Conclusions: As COVID-19 pandemic deepens economic and social stress coupled with movement restriction and social isolation measures, gender-based violence is increasing exponentially, and trap women and girls. The physical and psychological costs of violence against women and girls are substantial. Globally, the estimated global cost of violence against women and girls is 1.5 Trillion women where nearly $1 / 2$ amount of the world population in lockdown due to COVID-19. Hence, it has a relationship of violence against women and girls and surveillance of COVID-19 outbreak globally. In line with problems identified, civil society organizations and governments should work collaboratively with the whole society at home, institutions and public in general.
\end{abstract}

Keywords: COVID-19; Pandemic; Sexual \& reproductive health; Violence against women

DOI: $10.7176 /$ RHSS/10-21-01

Publication date: November $30^{\text {th }} 2020$

\section{Introduction}

In 31 December 2019, an outbreak of a respiratory disease associated with a novel coronavirus was reported in the city of Wuhan in a wet market, the Hubei province of the People's Republic of China [1; 2]. COVID-19 outbreak was first reported in Wuhan, China. On 9 January 2020, China CDC reported a novel coronavirus as the causative agent of this outbreak, coronavirus disease 2019 (COVID-19) and has spread to more than 50 countries [3]. WHO declared COVID-19 as a Public Health Emergency of International Concern (PHEIC), on 30 January 2020[4]. Coronaviruses $(\mathrm{CoV})$ are a large family of viruses that cause illnesses ranging from the common cold to more severe diseases, such as Middle East Respiratory Syndrome (MERS-CoV) and Severe Acute Respiratory Syndrome (SARS-CoV). A novel coronavirus is a new strain that has not been previously identified in humans. The virus has spread worldwide rapidly and on March 11, 2020, the World Health Organization declared Coronavirus Disease 2019 (COVID-19) a pandemic $[1 ; 3 ; 4 ; 5 ; 6]$.

As a Report of the WHO-China Joint Mission on (COVID-19 indicated the early cases identified in Wuhan are believed to be have acquired infection from a zoonotic source as many reported visiting or working in the Wuhan Wholesale Seafood Market. As of 25 February, an animal source has not yet been identified [7]. But, COVID-19 is a zoonotic disease, in other words, a disease caused by the transfer of a pathogen from animals to humans [8].

Additionally, Coronavirus Disease 2019 (COVID-19) is an infectious respiratory disease caused by severe acute respiratory syndrome coronavirus SARS-CoV-2 virus [9; 10]. COVID-19 is caused by a new type of coronavirus which was previously named 2019-nCoV by the World Health Organization (WHO). It is the seventh member of the coronavirus family, together with MERS-nCoV and SARS-nCoV that can spread to humans [4].

The Coronavirus virus is thought to spread mainly from person-to-person, including: between people who are 
in close contact with one another (within about 6 feet). Through respiratory droplets produced when an infected person coughs or sneezes. These droplets can land in the mouths or noses of people who are nearby or possibly be inhaled into the lungs. It may be possible that a person can get COVID-19 by touching a surface or object that has SARS-CoV-2 on it and then touching their own mouth, nose, or possibly their eyes, but this is not thought to be the primary way the virus spreads [9]. Coronavirus disease 2019 (COVID-19) is the virus typically spreads from person to person via respiratory droplets produced during coughing, and common symptoms include fever, cough, and shortness of breath and diarrhea [4;9;10].The clinical presentations of COVID-19 range from no symptoms (asymptomatic) to severe pneumonia; severe disease can lead to death [3]. But, in more severe cases, COVID-19 can cause pneumonia and even death [4].According to the CDC, symptoms of COVID-19 may appear in as few as 2 days or as long as 14 days after exposure[9].

COVID-19 is a serious global pandemic with more than 1 million confirmed cases and 64,000 deaths [11].While about $97-99 \%$ of individuals infected with coronavirus recovers, a high proportion of cases require hospitalization, and people over 65 and those with some underlying medical conditions experience higher mortality. As the virus spreads, the COVID-19 pandemic has the potential to quickly overwhelm health systems [12].It has spread from China to many other countries around the world, including the United States. The first case of COVID-19 in the United States was reported in January 2020 and the first death in February 2020, both in Washington State. Since then, the number of reported cases in the United States has increased and is expected to continue to rise [13].

Depending on the severity of COVID-19's international impacts, outbreak conditions-including those rising to the level of a pandemic-can affect all aspects of daily life, including travel, trade, tourism, food supplies, and financial markets[9]. While cases are currently concentrated in Europe, East Asia, and the Americas, the COVID19 pandemic now spans 183 countries. The potential impact in countries in the Caribbean, Africa, and Southern Asia, which may have lower-capacity health systems and large vulnerable populations, is still unknown [12].Numbers are expected to continue rising exponentially in the coming days, weeks, and months. Initial research indicates that older persons are most likely to suffer serious complications from COVID-19 and that men are more likely to experience high mortality rates than women, but this analysis may change as COVID-19 more data becomes available [14]. Regardless, all vulnerable populations will experience COVID-19 outbreaks differently. Until recently, the transmission of COVID-19 to developing countries or those experiencing ongoing humanitarian emergencies had been limited. Access constraints and poor health and sanitation infrastructure are obstacles to disease prevention and treatment under the best of circumstances; when coupled with gender inequality and, in some cases, insecurity, public health responses become immeasurably more complex[15], but such transmission is now occurring. Development and humanitarian settings pose particular challenges for infectious disease prevention and control [16].

\section{Methods}

This systematic review summarizes all of the studies that were conducted on the impacts of COVID-19 and violence against women on women health and human rights such as, its impacts on women's sexual and reproductive rights, and socio-economic opportunities. Due to the rationale that COVID-19 is new for humans, there is limited scientific studies are existed. So, the systematic selection of case reports, clinical trials, health institutions guidelines, forum reports, commentators, editor's letters, and available indexed articles/journals were undertaken to conduct this study. The author conducted the literature search on March 20 up to 02 May2020, where the existing quantitative and qualitative data included in this review. Hence, specific concerns about violence against women and COVID-19 that includes issues which are relevant for women health and women human rights are included.

\section{Sources and Study selection}

Relevant literature in relation of violence against women and COVID-19 was identified and searched by MEDLINE and PubMed. According to the pre-determined protocol, the author systematically searched for all eligible reports, full reports or letters with original data written in English. Eligible studies and reports were crosssectional studies, case serious, working papers, case series, and clinical trials. So, the literature search on $20 \mathrm{March}$ 2020 and restricted to 02 may 2020 ,where all articles or reports conducted until this time were incorporated.

All related English version of the literature that related to COVID-19 and its impacts on women and girls were reviewed. Although an extensive literature search was undertaken for this systematic review, this review is not meant to summarize all that is known about the impacts of COVID-19 and Violence against women to women health and human rights after 02 May 2020 that are not covered. Rather, it is meant to provide a brief summarize and reviewed systematically on the COVID-19 pandemic outbreak to orient the reader and to highlights to lesson learned and to focus on the important aspects of the pandemic outbreak and its impact on women and girls that are of particular relevance for health-practitioners, gender specialist, health institutions and humanitarian agencies. 


\section{Results and Discussions}

Coronavirus (COVID-19), declared as a pandemic by the WHO in 11 March 2020, has rapidly infected millions globally. Cases of novel coronavirus disease 2019 (COVID-19) are rapidly increasing globally [17; 18].A fastrising number of confirmed cases have been observed in all continents, with Europe at the epicentre of the outbreak at this moment [19]. As of 26 March 2020, a total number of 480446 cumulative cases of COVID-19 have been reported in 175 countries and regions, including 22030 confirmed deaths, the majority of which have been reported in Italy (7503), Spain (4089) and China (3169)[20]. In Spain, as of 25 March 2020, most of those who have died were elderly, about $96 \%$ of deaths were in those over 60 years old, and $45 \%$ had pre-existing health conditions including cardiovascular disease (31\%)5. With 120859 deaths in 2018, cardiovascular disease (CVD) is the leading cause of death in Spain (28.3\%) [20; 21].Sex-disaggregated data for CVD in Spain show differences in mortality between men (46.3\%) and women (53.7\%). Surprisingly, although men (51\%) and women (49\%) are getting infected by COVID-19 at similar rates, men have been dying from COVID-19 at a significantly higher rate (4.4\%) than women $(2.5 \%)$, and the sex differences regarding vulnerability in those with COVID-19 and preexisting CVD seem to be again reflected in men (35\%) and women (26\%)[22].However, the hospitalization rates were higher for those aged 60 years and above. Estimates of crude case-fatality for Germany, Italy and Spain showed that both the risk and absolute numbers of deaths rapidly increased with age for those aged 60 years and above in each country. Among hospitalized cases, severe illness was reported in $15 \%$ of cases, and death occurred in $12 \%$ of these cases, with higher case-fatality rates in older adults [3;22].

As of April 5, 2020, more than 1.2 million cases have been confirmed and 70,000 deaths have been reported in more than 180 countries[18].Several studies have rapidly provided crucial data (e.g., incubation period) related to various aspects of the novel coronavirus (SARS-CoV-2: severe acute respiratory syndrome coronavirus-2) infection [23].As of April 9, 2020, the coronavirus disease 2019 (COVID-19) pandemic had resulted in 1,521,252 cases and 92,798 deaths worldwide, including 459,165 cases and 16,570 deaths in the United States [13; 24]. The virus displays unique and deadlier characteristics than other annual flu viruses. This primer lays a foundation of epidemiologic background for COVID-19, explores keys to success to disease suppression and economic impacts during the pandemic, and reviews potential therapeutic resolution of the virus. The pace and maturity of infection is highly variable by region, largely hinging on speed and strength of government response [17].

Here, pre-existing gender and intersectional inequalities often worsen during a crisis, including public health emergencies. Tragically, these inequalities are not consistently included as part of global frameworks and policies [25].Recognizing the extent to which disease outbreaks affect women, girls, men and boys, people of different genders, and at-risk and marginalized groups in specific ways is fundamental to understanding the impacts of a health emergency in order to create effective, responsive and equitable policies, preparedness plans and responses [26].

Notably, violence against women and girls is a global human rights violation and public health problem, and a substantial development challenge. It affects women throughout the world, and crosses cultural and economic boundaries $[27 ; 28 ; 29]$.Violence against women is a public issue and encompasses virtually all spheres of public relations. It influences various spheres of social life, including public health, protection of juvenile's rights and social and economic welfare. Domestic violence is a global phenomenon without national, economic, religious, geographic and cultural borders. Violence on woman is mostly performed in her direct social environment affecting the physical and mental health of the woman. Violence has negative consequences for social welfare, children, families and community. Domestic violence restricts the woman's right to be involved in social life Studies conducted reveal the complexity of domestic violence character, variety of its causes and need for intersectorial cooperation $[29 ; 30]$.

In the current novel coronavirus outbreak (COVID-19), as of mid-March 2020, there are already reports from Australia, Brazil, China and the United States suggesting an increase in violence against women and children. In China's Jianli County (Central Hubei province), the police station reported receiving 162 reports of intimate partner violence (IPV) in February — which was three times the number reported in February 2019 [31]. Globally, 243 million women and girls aged from 15-49 have been subjected to sexual and /or physical violence perpetuated by an intimate partner in the previous 12 months. As estimated by UN, the estimated global cost of violence against women and girls is 1.5 Trillion women where nearly $1 / 2$ amount of the world population in lockdown due to COVID-19[32].

The COVID-19 pandemic has been the fastest-moving global public health crisis in a century, causing significant mortality and morbidity and giving rise to daunting health and socio-economic challenges [33]. As COVID-19 disrupts health systems and affects human health globally, it is crucial to protect those most impacted by COVID-19, sustain gains made to address other infectious diseases, and maintain people's access to life-saving health services. Stigma and discrimination experienced by KP members in health care settings limit access to and uptake of HIV services and will also likely affect their access to COVID-19-related services. Moreover, for KP individuals who are HIV-negative, the COVID pandemic may reduce their access to pre-exposure prophylaxis (PREP) and other prevention services. A critical priority during the COVID-19 pandemic is ensuring continuity 
of treatment and support for viral suppression among people living with HIV (PLHIV) and helping those who are at risk of HIV acquisition remain HIV negative [12;33].

Women and girls with chronic conditions, weakened immune systems (living with HIV, malaria, tuberculosis, etc.) or experiencing malnutrition appear to be particularly at risk of contracting COVID-19. Older women are more likely to have no or lower pensions and live in poverty, a manifestation of life-long inequality and discrimination. This may in turn exacerbate the impact of the virus, and their access to protective items, food $\&$ water, information and health services [34].

As it can be understand from different efforts, policies and public health efforts have not addressed the gendered impacts of disease outbreaks [35]. The response to coronavirus disease 2019 (COVID-19) appears no different. We are not aware of any gender analysis of the outbreak by global health institutions or governments in affected countries or in preparedness phases. Recognizing the extent to which disease outbreaks affect women and men differently is a fundamental step to understand the primary and secondary effects of a health emergency on different individuals and communities, and for creating effective, equitable policies and interventions. Although sex-disaggregated data for COVID-19 show equal numbers of cases between men and women so far, there seem to be sex differences in mortality and vulnerability to the disease [36]. Simultaneously, data from the State Council Information Office in China suggest that more than $90 \%$ of health-care workers in Hubei province are women, emphasizing the gendered nature of the health workforce and the risk that predominantly female health workers incur [37].

Principally, gender-based violence occurs in all countries and economic and social groups. It undermines the health, dignity, security and autonomy of its victims. To estimate the impact of the COVID-19 pandemic on efforts to end gender-based violence, Avenir Health modelled a delay in the scale-up of prevention efforts as attention and resources are devoted to COVID-19 and an increase in violence during the period of lockdown. Assuming a slow start to the scale-up of prevention programs (i.e., a 2-year delay in 2020 and 2021), followed by a rapid expansion of prevention programs in the middle of the decade, an estimated 2 million additional instances of intimate partner violence (IPV) in 2020-2021 are expected. This translates to almost 200 million fewer cases of violence being averted by 2030 , a reduction of about $1 / 3$ in progress in ending gender-based violence [33].

In similar manner, gender-based violence and domestic violence is also a major concern of SRH and rights, and the consequences of enforced self-quarantine or compulsory quarantine policy to contain the outbreak are unknown. Evidence shows that, quarantine leads to negative psychological effect, including post-traumatic stress symptoms, confusion and anger [38]. Quarantine might, therefore, increase the risk of gender-based violence and domestic abuse, which have been observed in other major disease outbreaks[39].

Globally, more than $35 \%$ of women will experience GBV in their lifetime. In humanitarian crises, compounding factors, such as increased anxiety and stress levels and economic hardships, can further increase GBV rates [40]. Women's rights activists in China have reported that domestic violence cases have risen dramatically as people across much of the country have been quarantined during the coronavirus outbreak. Wan Fei, a retired police officer and founder of an anti-domestic violence nonprofit in Jingzhou, reports that "the epidemic has had a huge impact on domestic violence". According to our statistics, $90 \%$ of the causes of violence are related to the COVID-19 epidemic [41].

As a result of COVID-19, compounded economic impacts are felt especially by women and girls who are generally earning less, saving less, and holding insecure jobs or living close to poverty. While early reports reveal more men are dying as a result of COVID-19, the health of women generally is adversely impacted through the reallocation of resources and priorities, including sexual and reproductive health services. As the COVID-19 pandemic deepens economic and social stress coupled with restricted movement and social isolation measures, gender-based violence is increasing exponentially. Many women are being forced to 'lockdown' at home with their abusers at the same time that services to support survivors are being disrupted or made inaccessible economy, security to social protection, the impacts of COVID-19 are exacerbated for women and girls simply by virtue of their sex[42]. Additionally, the social and economic costs of violence against women and girls are substantial, with broader costs associated with delivering services to victims, as well as the costs related to the criminal justice response The global cost of violence against women and girls (public, private and social) is estimated at approximately 2 per cent of global gross domestic product (GDP), or US\$1.5 trillion in the world [32; 42].

As mounting evidences showed, outbreaks exacerbate age, gender and disability inequalities and place women, girls, and other vulnerable populations-such as LGBTQIA individuals at increased risk of gender-based violence (GBV) and intimate partner violence (IPV). In fact, IPV may be the most common type of violence that women and girls experience during emergencies [43], resulting in profound physical and psychosocial harm. In the event of COVID-19 outbreaks in development and humanitarian settings, IPV incidents may surge if movement restrictions or quarantine measures are put in place [44]. However, at the time when many women and girls need GBV and IPV services more than ever, evidence suggests that those services are likely to decrease as resources are diverted to dealing with access to sexual and reproductive health (SRH) services, such as clean and safe deliveries, contraceptives, and pre- and post-natal health care[33]. Outbreaks could also result in disruptions to 
mental health and psychosocial support services (MHPSS), putting the individuals participating in them at risk [15].

Hence, it can be understand that, there is a high risk of GBV increasing, during the COVID-19 pandemic as movement restrictions trap women and children [45]. Potential loss of income due to self-isolation, potential lack of information regarding which GBV services remain available, and fears of contracting the virus at service points could create multiple barriers whereby survivors of GBV may find themselves in a near impossible situation: unable to seek support, unable to access services, and unable to leave their abusers[26].

As findings on the impact of COVID-19 in ending GBV indicates, the COVID-19 pandemic is likely to undermine efforts to end gender-based violence through two pathways such as reducing prevention and protection efforts, social services and car; increasing the incidence of violence. COVID-19 pandemic is likely to cause a onethird reduction in progress towards ending gender-based violence by 2030; if the lockdown continues for 6 months; 31 million additional gender-based violence cases can be expected. For every 3 months the lockdown continues, an additional 15 million additional cases of GBV are expected. Projections show that if violence increases by 20 per cent during periods of lockdown, there would be an additional 15 million cases of intimate partner violence in 2020 for an average lockdown duration of 3 months, 31 million cases for an average lockdown of 6 months, 45 million for an average lockdown of 9 months, and 61 million if the average lockdown period were to be as long as one year. These projections are global-inclusive of all 193 United Nations member states, and account for the high levels of underreporting seen with VAW. Together, they amount to an additional 15 million cases of gender-based violence for every 3 months the lockdown continues. Resources to provide support, counseling and post-rape care during the pandemic will also be strained [33].

Notably, in lockdown and violence, as important as mandatory lockdowns, quarantine, and self-isolation are these measures can have harmful effects on those in already violent situations. Individuals, particularly women are essentially trapped with their abuser with no physical respite from the abusive relationship [46]. The abuser can also use the virus to further isolate their victim from family, friends, and social networks as well as from the services that could support them [47]. Where women have access to technology, on-line violence against women is also increasing. Before COVID-19, one in 10 women in the European Union reported having experienced cyberharassment since the age of 15 (including having received unwanted, offensive and sexually explicit emails or SMS messages or offensive, inappropriate advances on social networking sites)[48].

Likewise, during COVID-19 and moving restrictions, the use of online platforms has increased in the last few weeks. This has been used by some as an opportunity to groom young people into exploitative situations. According to Europol, online activity by that seeking child abuse material is increasing [49]. Millions of women and girls are using videoconferences frequently, sometimes daily, to work and study. According to diverse media outlets, social media posts and women rights experts, different forms of on-line violence are on the rise including stalking, bullying, sexual harassment, and sex trolling. Examples include unsolicited pornographic videos while they are dialing into a social event via a virtual chat room. Alongside increased reports of VAWG, we are also seeing greater complexity of violence [32].

In fact that, psychosocial wellbeing is also a major issue for adolescents exposed to conflict, displacement or violence,; which is not uncommon in humanitarian settings. Moreover, MHPSS caseloads will likely increase during COVID-19 outbreaks, as frontline health workers, women and girls with caregiving burdens, and community members fearful of becoming infected or infecting others may all experience stress and trauma relating to the outbreak[15].

Women's fear and experience of sexual violence and other forms of violence in public spaces is also likely to escalate, as we have already seen in the Philippines and India, as COVID-19 takes a foothold in urban and rural areas, where social distancing has emptied streets, and transport, except for those who are performing essential services. Workers in healthcare professions at the forefront of the COVID-19 response, 70 per cent of whom are women, also face multiple risks to their health, wellbeing, and safety. There have been increased reports of both physical and verbal attacks on healthcare workers in China, Italy and Singapore [32].

As we already know, some countries have imposed mass quarantine and travel restriction measures for people entering their territory, which may entail confinement in accommodation in conditions that place women and their children at a heightened risk of violence, among other challenges. As distancing measures are put in place and people are encouraged to stay at home, the risk of intimate partner violence is likely to increase [50].

This is similar during the 2014-16, West African outbreak of Ebola virus disease; gendered norms meant that women were more likely to be infected by the virus, given their predominant roles as caregivers within families and as front-line health-care workers [51]. Women were less likely than men to have power in decision making around the outbreak, and their needs were largely unmet [52]. For example, resources for reproductive and sexual health were diverted to the emergency response, contributing to a rise in maternal mortality in a region with one of the highest rates in the world [53]. In similar manner, during the Zika virus outbreak, differences in power between men and women meant that women did not have autonomy over their sexual and reproductive lives[54], which was compounded by their inadequate access to health care and insufficient financial resources to travel to 
hospitals for check-ups for their children, despite women doing most of the community vector control activities[55].

Basically, the acute and emergency maternal and reproductive health services may be hit hardest, with limited facilities for isolation areas to assess and care for women in labour and the newborn. Lifesaving procedures, from caesarean sections to abortion care, may be delayed due to staff deployment and shortages and lack of infrastructure, e.g. operation theatres and ward space. Women who have to spend time recovering in hospital wards in low-income countries are often reliant on relatives for food and care, making isolation and infection control measures difficult and intensifying the risks of COVID-19 spread. The effects of the pandemic could also affect routine health care services. Clinic appointments are rare in low-income settings and people can wait long hours at crowded clinic waiting areas for antenatal care, contraceptive counseling or other reproductive health services, which will increase risk of infection transmission. Cancellation of routine clinics may be necessary with deployment of staff away to acute care. Those most disadvantaged may incur costs, suffer travel for long distances and other inconveniences needlessly, or even not attend for care at all $[5 ; 55]$.

Findings indicates that, this reduction in contraceptive use could have dire consequences for women, from 325,000 unintended pregnancies, the estimate for minimal disruptions for 3 months, up to a staggering 15 million unintended pregnancies if high disruptions are seen for a period of 12 months [56].This indicates that, sexual and reproductive health $(\mathrm{SRH})$ and rights is a significant public health issue during the epidemics. Beyond the clinical scope of SRH, we should not neglect the impacts at the health system level and disruptions or interruptions in regular provision of SRH services, such as pre and postnatal checks, safe abortion, contraception, HIV/AIDS and sexually transmitted infections. Furthermore, other aspects merit attention such as the potential increase of genderbased violence and domestic abuse, and effects of stigma and discrimination associated with COVID-19 and their effects on SRH clients and health care providers [19].

The impact of COVID-19 on ending unmet need for family planning, women are refraining from visiting health facilities due to fears about COVID-19 exposure or due to movement restrictions and, supply chain disruptions are limiting availability of contraceptives in many places, and stock-outs of many contraceptive methods are anticipated within the next 6 months in more than a dozen lowest-income countries. It has also a product shortages and lack of access to trained providers or clinics mean that women may be unable to use their preferred method of contraception, may instead use a less effective short-term method, or may discontinue contraceptive use entirely. Some 47 million women in 114 low- and middle-income countries are projected to be unable to use modern contraceptives if the average lockdown, or COVID-19-related disruption, continues for 6 months with major disruptions to services $[33 ; 56]$.

Generally, the impact of the COVID-19 pandemic on family planning and ending gender-based violence, female genital mutilation and child marriage has complex and needs collaborative efforts. It can be deduced that, safe and confidential access to health services can be undermined, as pre-existing barriers will be exacerbated in the health emergency. Such barriers include social norms and gender-based discrimination, criminalization (e.g. of abortion, same-sex sexual conduct, sex work, HIV transmission, etc.), restricted freedom of movement, a lack of income, need of third-party authorizations, and lack of child care options. There are also reports of families preventing women and girls infected with COVID-19 from seeking treatment because of cultural and religious prohibitions and related family honor concerns [34].

In terms of labour force, women comprise more than 75 percent of the health care workforce in many countries [57], which increases the likelihood that they will be exposed to infectious diseases. Evidence suggests that during past public health emergencies, resources have been diverted from routine health care services toward containing and responding to the outbreak.

Research has also shown that $70 \%$ of workers in the health and social sector are women [58]. Tragically, maternal health is already a critical issue for women around the world: $61 \%$ of maternal deaths worldwide occur in fragile states, many of them affected by conflict and recurring natural disasters [59]. Adolescent girls, who have unique SRH needs, may be particularly affected. In addition to the caregiving burden, social norms in some contexts dictate that women and girls are the last to receive medical attention when they become ill, which could hinder their ability to receive timely care for COVID-19. This could have serious implications for older women or those with chronic conditions or weakened immune systems such as women infected with HIV, malaria, or tuberculosis-who appear to be at greater risk of contracting COVID-19 or for women and girls experiencing malnutrition [60].

However, in emergency settings, female health workers are at heightened risk to both routine and severe violence. Some forms of violence in the world of work affect women uniquely, such as "maternity harassment" or "maternal mobbing" which is widespread around the world [61]. As the currents study findings pointed out, the optimal management of pregnant women with COVID-19 poses multiple challenges, ranging from screening for the virus on admission to labor and delivery, management of the acutely ill parturient, anesthesia, and protection of healthcare personnel. Although originally thought that pregnant women with COVID-19 were no more likely to develop severe morbidity or die, recent reports suggest that a subset may develop multiple organ failure and even die. Given that normal pregnant women have evidence of increased generation of thrombin and a 
prothrombotic state, as well as increased intravascular inflammation which is exaggerated in the context of infection, such patients may be at an increased risk for thrombosis when affected by COVID-19[62].

In case of the household power, women's health care is not determined solely by the provision of health-care treatments, but also by whether women have free and safe access to such services [63]. In contexts where men hold the majority or all decision-making power in the household, this can limit women's access to health and SRHR services, particularly if they have restricted freedom of movement or if they have no control over household finances having less individual agency and decision-making power than their male[26]. Evidence shows that pregnant workers, as well as women and men returning from maternity or parental leave, can experience harassment and bullying by co-workers, subordinates or superiors [61].

Another important point is the impact of COVID-19 on ending FGM; it could have far-reaching impacts on the effort to end female genital mutilation. Due to COVID-19 disruptions, we anticipate a $1 / 3$ reduction in the progress towards ending FGM by 2030 and due to pandemic-related disruptions in prevention programs, 2 million FGM cases could occur over the next decade that would otherwise have been averted. It has also an impact on ending child marriage. COVID-19 will disrupt planned efforts to end child marriage and cause wide-reaching economic consequences. Regarding the impact of COVID-19 on ending female genital mutilation, an estimated 200 million women alive today have undergone FGM, which is a violation of girls' human rights and is often a precursor to child, early and forced marriage, which usually ends a girl's education and dims her economic prospects [33].

WHO also estimates, more than $30 \%$ of women worldwide have experienced either physical or sexual partner violence $[27 ; 28] .7 \%$ of women worldwide have experienced non-partner sexual assault [64]. About 100-140 million girls and women worldwide have undergone female genital mutilation (FGM) and more than 3 million girls are at risk for FGM every year in Africa alone. Our reviewed studies cover a broad range of intervention models, and many forms of violence- i.e, intimate partner violence, non-partner sexual assault, female genital mutilation, and child marriage [29;33].

In meanwhile, available data show that less than 40 per cent of the women who experience violence seek help of any sort. Among those who do, most look to family and friends. Less than 10 per cent of those women seeking help seek help from the police. The existing crisis of VAWG is likely to worsen in the context of COVID-19[32]. In the 21st century, public consolidation against all forms of domestic violence has become a pressing issue. Although, domestic violence is considered a human rights violation and Georgian society is becoming increasingly open and intolerant against this problem, studies show that domestic violence is a widespread phenomenon throughout Georgia. $78 \%$ of women still consider that domestic violence issues can be discussed within family only, while $34 \%$ of women justify men battering their wives in certain cases and do not regard as it as a violation of law[30].

As findings pointed out, the issues of sexual exploitation and abuse is also another crucial problem in COVID19 pandemic outbreak. An overall economic downturn can result in a spike in sexual exploitation and abuse. Atrisk groups-such as those women among others-who are struggling financially may be forced or coerced to provide sex in exchange for food [65].

This was seen during the West Africa Ebola outbreak, with single female-headed households at additional risk [66]. Emerging evidences as well as research undertaken following the West Africa Ebola outbreak, suggests that the COVID-19 pandemic has the potential to increase the risks of sexual exploitation and violence by state officials and armed guards [67].

The Zika virus outbreak in 2015 provides one example. Infection with Zika virus causes pregnancy complications and specifically, congenital deformities in fetal brain development, with microcephaly. In Latin America, the epidemic sparked a debate on the need to extend abortion laws to protect women's rights to safe abortion [68], and raised concerns of reproductive and social justice which continue to this day [69]. The Ebola virus outbreak in West Africa between 2014 and 2016 revealed that, gendered norms of women as family caregivers and frontline health workers led them to be at higher risk of infection [69].

As the findings also showed, in the clinical course of Middle East Respiratory Syndrome coronavirus (MERSCov) infection in a pregnant woman who acquired the infection during the last trimester of pregnancy during a large hospital outbreak, the severity of viral pneumonia in pregnancy is evidently related to physiological and immunological changes that result in a shift from cell-mediated to humoral-mediated immunity. Pregnant women with severe acute respiratory syndrome (SARS) appear to have a worse clinical outcome and a higher mortality rate compared to non-gravid women [70; 71]. Rates of maternal mortality, stillbirth, spontaneous abortion, and preterm delivery have all been elevated in viral pneumonia such as influenza-A, virus subtype H1N1, and SARS. While there are no clinical or serologic reports suggesting transmission of SARS coronavirus to the fetus, vertical transmission has been reported for H1N1 and Respiratory Syncytial Virus (RSV) [72].

Where the members of key populations (KPs), including sex workers (SWs), men who have sex with men (MSM), people who inject drugs (PWID), and transgender (TG) people are particularly vulnerable to COVID-19. Several factors that elevate KPs' risk of HIV acquisition may also place them at higher risk of acquiring 
coronavirus, such as high mobility and close physical contact with others through social and sexual practices. KP individuals living with HIV who are not on antiretroviral therapy (ART) and not virally suppressed may have a compromised immune system, which may place them at higher risk of coronavirus acquisition and COVID-19 morbidity and mortality [12].

However, economically, following travel bans, border closures and quarantine measures, many workers cannot move to their places of work or carry out their jobs, which have knock-on effects on incomes, particularly for informal and casually employed workers especially women and girls due to the COVID-19 pandemic outbreak[73]. In many countries women are concentrated in the low-wage and informal sector jobs that are highly prone to disruption. Women are also over-represented in the hospitality (hotels, restaurants), retail and service industries that have been among the hardest hit by the response to COVID-19. Women and girls in many contexts may have travel longer distances to collect food and water for household use, exposing them to increased risk of contracting COVID-19 and gender-based violence. Women human rights defenders in Kenya, South Africa, and Ethiopia emphasized that the safety of women is at risk as they rise early or stay late at water points and queue for water[34].

Likewise, the closure of schools to control COVID-19 transmission in China, Hong Kong, Italy, South Korea, and beyond might have a differential effect on women, who provide most of the informal care within families, with the consequence of limiting their work and economic opportunities. Travel restrictions cause financial challenges and uncertainty for mostly female foreign domestic workers, many of whom travel in Southeast Asia between the Philippines, Indonesia, Hong Kong, and Singapore [36].

On the other hand, individuals forced to live with abusive families or to hide their sexual orientation or gender identity in order to have access to shelter, all while dealing with increased social isolation may also experience increased anxiety and depression. Additionally, physical distancing measures to prevent the spread of coronavirus may affect the livelihood and safety of sex workers; many will have fewer clients, increasing the risk of homelessness and the need to accept riskier clients. The closing of bars and other hot spots may also cause sex workers to move from a more protected environment to street-based activities [12].

Globally, women perform $76.2 \%$ of the total hours of unpaid care work, more than three times as much as men. During public health crises, such as COVID-19, this may involve taking care of sick family members. As health systems-particularly weak ones-become overwhelmed, women will likely bear the burden of caring for patients that the health system cannot, increasing women's risk of exposure to the virus [74].

Additionally, the unpaid care work has increased, with children out-of-school, heightened care needs of older persons and overwhelmed health services. Lastly, the global pandemic has led to a significant increase in restrictions on the freedom of movement of people worldwide and worrisome reports on the misuse of emergency measures to further erode human rights and the rule of law [42]. Therefore, economic abuse is a prevalent correlative to other forms of GBVAWG. In the context of the unemployment and other adverse economic impacts associated with the COVID-19 pandemic, women and their children may be particularly vulnerable to economic abuse and associated deprivations during this time. There may be particular risks for women who cannot purchase essential goods (food and medicine) because they are prevented by an abusive partner from leaving their home, or fear leaving their children with the abusive partner, or are denied the funds for those purchases [50].

The COVID-19 pandemic is also expected to increase levels of violence. In the immediate term, the largest contributor is likely to come from the effects of stay-at-home orders and movement restrictions, which could increase women's exposure to violent partners. Mounting household tensions and economic stresses could also play a role. There are already indications that violence incidence is indeed growing, including increases in calls to violence prevention hotlines and media reports of rising domestic abuse and homicide [56].

On 5 April, the Secretary-General called for a global ceasefire and an end to all violence everywhere so that we can focus our attention and resources on stopping this pandemic. Violence against women and girls is increasing globally as the COVID-19 pandemic combines with economic and social stresses and measures to restrict contact and movement. Crowded homes, substance abuse, limited access to services and reduced peer support are exacerbating these conditions. There are already many deeply concerning reports of increased violence against women around the world, in many cases of upwards of $25 \%$ in countries with reporting systems in place. In some countries reported cases have doubled and also likely to reflect only the worst cases. Without access to private spaces, many women will struggle to make a call or to seek help online. Alongside the increase in numbers, violence against women is taking on new complexity: exposure to COVID-19 is being used as a threat; abusers are exploiting the inability of women to call for help or escape; women risk being thrown out on the street with nowhere to go. Some domestic violence shelters are full; others have had to close or have been repurposed as health centers [42].

The impact of measures to curb COVID-19 is thus not spread evenly, but bound to disproportionately affect certain groups, including victims and survivors of domestic violence, homeless women, older women and women and girls with disabilities. Women and girls who are deprived of their liberty, displaced, refugees, asylum seekers, migrants and those living in conflict affected areas are particularly at risk during the COVID-19 emergency. For 
example, evidence from refugee camps and humanitarian assistance zones confirms that where families or individuals are held or housed in close proximity for extended periods of time, rates of violence against women and violence against children are high[50;24].

EU also noted that, COVID-19 has an impact on persons in a number of vulnerable situations, namely: people living in institutional settings, including nursing homes, prisons and refugee camps or reception facilities; particular groups, including persons with disabilities, older people, Roma and Travellers, and women and children at risk of domestic violence. Measures such as physical distancing are not effective in overcrowded settings, yet failure to contain the spread of COVID-19 in such institutions, poses serious risks to the right to health, and sometimes even to life [75].

Violence is already highly stigmatized, as a result of which women, girls, and sometimes their families fear reporting or seeking services or justice. The stigma combines with an overall lack of trust in the ability or motivation of providers and justice systems to provide redress and further discourages women. Any responsebased intervention must address women's trust of and access to the service provider and be sensitive to the possibility that reporting may induce further violence [76].

In case of women's voices, women should not be further burdened, particularly since much of their labour during health crises goes underpaid or unpaid [26].That said, incorporating women's voices and knowledge is critical at all stages of outbreak preparedness and response. Social norms and gender roles often restrict women's ability to participate in decision-making processes, and this impacts the degree to which their specific needs are taken into consideration, both during the response itself and later, during the design and implementation of economic relief packages, new services, or other support systems[77].

As a summative point, UN noted on the impact of COVID-19 to gender-based violence against women and girls indicates that gender-based violence against women and girls (GBVAWG), with intimate partner violence as its most common form, is highly prevalent in many societies, where it erodes social cohesion and development. Emergency situations, such as the ongoing COVID-19 pandemic, aggravate the threat of GBVAWG to individuals, families and societies. Indeed the risk and consequences of GBVAWG may be exacerbated by lockdown policies implemented by many countries throughout the world, the disruption of economic, social and protective networks, sudden changes in family functioning, stress, increased substance use and decreased access to services [50].

Cognizance of the above, there is a high risk that all forms of gender-based violence (GBV) will increase during the COVID-19 pandemic, creating more demand and greater need for services. Women's rights activists in China have reported that domestic violence cases have raised dramatically as people across much of the country have been quarantined, potentially with abusers, during the coronavirus outbreak [41].

Globally, 1 in 3 women worldwide have experienced physical and/or sexual violence by an intimate partner or sexual violence by any perpetrator in their lifetime. Most of this is intimate partner violence. Older women and women with disabilities are likely to have additional risks and needs. The health impacts of violence, particularly intimate partner/domestic violence, on women and their children are significant. Violence against women can result in injuries and serious physical, mental, sexual and reproductive health problems, including sexually transmitted infections, HIV, and unplanned pregnancies [40]. However; it has become apparent that most cases of COVID-19 are the result of dissemination of the virus from asymptomatic individuals. Similarly, it increases the risk of COVID-19 transmission from mother to her infant or to other obstetrical patients on a shared antepartum or postpartum unit [78].

So, it can be understand that, staying at home is not the safest option for many women and children, as the home is often where they are at risk of sexual and other forms of violence, including homicide, physical abuse, sexual abuse, psychological abuse, economic abuse, neglect and/or coercive control. It is important to recognize that children who witness abuse are themselves victims of violence. Children who ordinarily live according to shared care arrangements are at particular risk if placed with an abusive parent during the COVID-19 emergency, including the trauma of being separated from the second parent and/or siblings [50].

Meanwhile, the COVID-19 pandemic continues to spread rapidly and unpredictably on a global scale. Developing countries and countries in humanitarian crisis that have no proper economic and health infrastructure will suffer the most [79]. Due to this rationale, in the face of violence, there is a gap between the humanitarian response in emergency situations and the failures of the relevant institutions to tackle and respond to every day GBV [80].As mounting evidences and history shows, in such pandemics, social inequality, particularly gender inequality is even more pronounced. Therefore, it is important that measures taken against the pandemic are gender-sensitive and that the positioning of different groups in society and the economy are considered, avoiding further deterioration of the situation, especially for marginalized groups. States are confronting the Coronavirus through emergency measures, but these do not always consider the different needs of women and men [55; 80].

\section{Conclusions and Recommendations}

Pandemic outbreaks, crises and times of unrest have been linked to increased interpersonal violence, including incidence of violence against women and children (VAW/C). Here, violence against women and girls is a global 
human rights violation and public health problem, and a substantial development challenge. It affects women throughout the world and is a universal issue, with great impact on victims/survivors, their families, and communities. The economic impact of COVID-19 result to the increment of financial strain on communities particularly in segments of the population that are already vulnerable especially women. Violence against women can result in injuries and serious physical, mental, sexual and reproductive health problems, including sexually transmitted infections, HIV, and unplanned pregnancies. The COVID-19 pandemic is also expected to increase levels of violence. Projections show that if violence increases by 20 per cent during periods of lockdown, there would be an additional 15 million cases of intimate partner violence or domestic violence in 2020 for average lockdown duration of 3 months. There is a high risk that all forms of gender-based violence (GBV) will increase during the COVID-19 pandemic, creating more demand and greater need for services. Therefore, it makes recommendations to be considered by all sectors of society, from governments to international organizations and to civil society organizations in order to prevent and respond to violence against women and girls, at the onset, during, and after the public health crisis with examples of actions already taken. It also considers the socioeconomic impact of the pandemic and its implications for violence against women and girls in the long-term.

\section{REFERENCES}

1. CDC.2020.Vital Statistics Reporting Guidance; Guidance for Certifying Deaths Due to Coronavirus Disease 2019 (COVID-19)- Report No. 3,April 2020 U.S. Department of Health and Human Services • Centers for Disease Control and Prevention • National Center for Health Statistics • National Vital Statistics System

2. Yu-Tao Xiang, Yuan Yang, Wen Li, Ling Zhang, Qinge Zhang, Teris Cheung, Chee H Ng. 2020. Timely mental health care for the 2019 novel coronavirus outbreak is urgently needed; www.the Lancet.com/psychiatry Vol 7 March 2020; Published Online; February 4, 2020; https://doi.org/10.1016/; S2215-0366(20)30046-8.

3. European Centre for Disease Prevention and Control, Coronavirus disease.2019. (COVID-19) pandemic: increased transmission in the EU/EEA and the UK - seventh update, 25 March 2020. Stockholm: ECDC; 2020.

4. Binti Hamzah FA, Lau C, Nazri H, Ligot DV, Lee G, Tan CL, et al. 2020. Corona Tracker: Worldwide COVID-19 Outbreak Data Analysis and Prediction. [Submitted]. Bull World Health Organ. E-pub: 19 March 2020. doi: http ://dx. doi. org/ 10.2471 /BLT. 20.255695Corona Tracker: World-wide COVID-19 Outbreak Data Analysis and Prediction, Corona Tracker Community Research Group

5. Julia Hussein. 2020. COVID-19: What implications for sexual and reproductive health and rights globally? Sexual and Reproductive Health Matters: 28: 1, 1746065, DOI: 10. 1080 /26410397.2020.1746065

6. Sonja A. Rasmussen., John C. Smulian.,John A. Lednicky.,Tony S. Wen., Denise J. Jamieson., 2020. Coronavirus Disease 2019 (COVID-19) and pregnancy: what obstetricians need to know; American Journal of Obstetrics \& Gynecology_https://doi.org/10.1016/j.ajog.2020.02.017.

7. WHO- China Joint Mission on COVID-19.2020. Report of the WHO-China Joint Mission on Coronavirus Disease 2019 (COVID-19); 16-24 February 2020

8. UN Economic Commission for Africa.2020. COVID-19 in Africa: Protecting Lives and Economieseca_covid_report_en_rev16april_5web(1)(1)

9. OSHA.2020. Guidance on Preparing Workplaces for COVID-19, U.S. Department of Labor Occupational Safety and Health Administration, Occupational Safety And Health Administration (OSHA) 3990-03 2020

10. Javier C. Vázquez1, Diego Redolar-Ripoll2.2020.COVID-19 outbreak impact in Spain: A role for tobacco smoking? Tob. Induc. Dis. $2020 ; 18$ (April) :30, ,https :// doi .org /10 .18332/tid/120005

11. Johns Hopkins University. 2020. Coronavirus COVID-19 Global Cases by the Center for Systems Science and Engineering (CSSE) at John Hopkins University. JHU April 5) JHU Link.

12. EPIC, USAID, and PEPFAR. 2020. Strategic Considerations for Mitigating the Impact of COVID-19 on KeyPopulation-Focused HIV Programs .Meeting Targets And Maintaining Epidemic Control (Epic) Project Cooperative Agreement NO.7200 AA19 CA0 0002

13. CDC.2020. Coronavirus disease 2019 (COVID-19): cases in U.S. Atlanta, GA: US Department of Health and Human Services, CDC; 2020. https:// www .cdc. gov/ corona virus /2019-ncov/cases-updates/cases-inus.html

14. Sharon Begley.2020. "Who Is Getting Sick, And How Sick? A Breakdown of Coronavirus Risk By Demographic Factors," March 3, 2020, https ://www .stat news .com /2020 /03 /03/who-is-getting-sick-andhow-sick-a-breakdown-of-coronavirus-risk-bydemographic- factors/.

15. Care.2020. Gender implications of COVID-19 outbreaks in development and humanitarian settings (1)

16. UN Office for the Coordination of Humanitarian Affairs (UN OCHA).2020. "Global Humanitarian Overview 2020, ” OCHA, December 4, 2020, https ://www .unocha .org/ sites/ unocha/files/GHO-2020_v9.1.pdf.

17. Oliver Wyman .2020.Responding to COVID-19 primer, Scenarios, and Implications; April 23, 2020 UPDATE 
18. Kunihiro Matsushita., Ning Ding., Minghao Kou., Xiao Hu., Mengkun Chen., Yumin Gao., Yasuyuki Honda., David Dowdy., Yejin Mok., Junichi Ishigami., Lawrence J. Appel.,.2020. The relationship of COVID-19 severity with cardiovascular disease and its traditional risk factors: A systematic review and meta-analysis// doi: https ://do i.org /10.1101/2020.04.05.20054155. medRxiv preprint

19. Tang Kun, Junjian Gaoshan and Babatunde Ahonsi .2020. Sexual and reproductive health (SRH): a key issue in the emergency response to the coronavirus disease (COVID19)outbreak:Reproductivehealth;ReproductiveHealth;17:59;https://doi.org/10.1186/s12978-020-0900-9.

20. Johns Hopkins University.2020. Coronavirus COVID-19 Global Cases by the Center for Systems Science and Engineering (CSSE) at Johns Hopkins University (JHU). https :// www.arcgis.com/apps/opsdashboard/index.html\#/ bda7594740fd40299423467b48e9ecf6. Published March, 2020. Accessed March 25, 2020.

21. World Health Organization.2020. Q\&A on coronaviruses (COVID-19). https://www. who.int/ news- room /q-a-detail/q- a corona viruses. Published March, 2020. Accessed March 25, 2020.

22. Worldometer. 2020. Age, Sex, Existing Conditions of COVID-19 Cases and Deaths. 29 February2020.https:/www.worldometers.info/coronavirus/coronavirus-age-sexdemogra phics/.

23. Lauer SA, Grantz KH, Bi Q, et al.2020. The Incubation Period of Coronavirus Disease 2019 (COVID-19) From Publicly Reported Confirmed Cases: Estimation and Application. Ann Intern Med 2020.

24. World Health Organization.2020. Corona virus disease 2019 (COVID-19) situation report -81. Geneva, Switzerland: World Health Organization; 2020. https:// ww .who .int/ docs /default- source/ coronaviruse /situation -reports /2020 0410 -sitrep -81 -covid19 .pdf?sfvrsnca96eb84_2

25. Julia Smith.2019. "Overcoming, the 'Tyranny of the Urgent': Integrating Gender Into Disease Outbreak Preparedness and Response," Gender \& Development, 27:2, 355-369, https://doi.org/10.1080/13552074.2019.1615288.

26. Christina Haneef, and Anushka Kalyanpur. 2020. Global Rapid Gender Analysis For Covid-19; Care + IRC GLOBAL RGA for Covid-19

27. Devries KM, Mak JY, García-Moreno C, et al.2013. Global health. The global prevalence of intimate partner violence against women. Science; 340: 1527-28.

28. Stöckl H, Devries K, Rotstein A, et al.2013. The global prevalence of intimate partner homicide: a systematic review. Lancet; 382: 859-65.

29. Mary Ellsberg, Diana J Arango, Matthew Morton, Floriza Gennari, Sveinung Kiplesund, Manuel Contreras, Charlotte Watts.2014. Violence against women and girls: Prevention of violence against women and girls: what does the evidence say? Serious, Lacent: www.thelancet.com Published online November 21, 2014 http://dx.doi.org/10.1016/S0140-6736(14)61703-7

30. Marine Chitashvili., Nino Javakhishvili., Luiza Arutiunov., Lia Tsuladze., Sophio Chachanidze.2010. National Research on Domestic Violence Against Women In Georgia Final Report; Tbilisi, 2010

31. Peterman, Potts, O’Donnell, Thompson, Shah, Oertelt- Prigione, and van Gelder, 2020. "Pandemics and Violence against Women and Children." CGD Working Paper 528. Washington, DC: Center for Global Development. https://www.cgdev.org/publication/ pandemics- and-violence-against-women-and-children

32. UN Women.2020. Issue-brief-covid-19-and-ending-violence-against-women and-girls-eng(1)

33. UNFPA.2020.Impact of the COVID-19 Pandemic on Family Planning and Ending Gender-based Violence, Female Genital Mutilation and Child Marriage ; Pandemic threatens achievement of the Transformative Results committed to by UNFPA . Interim Technical Note Information as of 27 April 2020; By UNFPA, with contributions from Avenir Health, Johns Hopkins University (USA) and Victoria University.

34. United Nations Human Rights Office of the Commissioner.2020. Covid-19 And Women's Human Rights: Guidance; Human Rights At The Heart Of Response Topics In Focus Covid-19 And Women's Human Rights ; 15 April 2020

35. Smith J.2019. Overcoming the "Tyranny of the urgent": integrating gender into disease outbreak preparedness and response. Gender Develop; 27: 355-69.

36. Clare Wenham, Julia Smith, Rosemary Morgan .2020. COVID-19: the Gendered impacts of the outbreak the Gender and COVID-19: Working Group †.The Lancet.com Vol 395 March 14, 2020/

37. Boniol M, McIsaac M, Xu L, Wuliji T, Diallo K, Campbell J.2019. Gender equity in the health workforce: analysis of 104 countries: Working Paper 1. Geneva: World Health Organization, 2019.

38. Brooks SK, Webster RK, Smith LE, Woodland L, Wessely S, Greenberg N, Rubin GJ. 2020. The Psychological Impact of Quarantine and How to Reduce It: Rapid Review of the Evidence. The Lancet; 395: 10227(912-920); Available at SSRN 3532534. .

39. Chynoweth SK, Amsalu R, Casey SE, McGinn T.2018. Implementing sexual and reproductive health care in humanitarian crises. Lancet; 391(10132): 1770-1.

40. WHO. 2020. COVID-19 and violence against women: What the health sector/system can do: Human Reproduction Programme; Research for Impact; 7 April 2020 
41. Axios. Bethany Allen-Ebrahimian.2020. China's Domestic Violence Epidemic. 7 March 2020.https://www.axios.com/china-domestic-violence-coronavirus-quarantine-7b00c3ba-35bc-4d16-afddb76ecfb28882.html.

42. UN.2020. Policy Brief: The Impact of Covid-19 on Women; 9 April 2020

43. International Rescue Committee (IRC).2015. “Private Violence, Public Concern," IRC, January 2015,https://www.rescue.org/sites/default/files/document/564/ircpvpcfinalen.pdf.

44. Zhang Wanqing.2020. "Domestic Violence Cases Surge During COVID-19 Epidemic,” Sixth Tone, March 2, 2020, http://www.sixthtone.com/news/1005253/domestic-violence-cases-surge-during-covid-19-epidemic.

45. The Alliance for Child Protection in Humanitarian Action.2019. Technical Note: Protection of Children during the Coronavirus Pandemic, Version 1, March 2019.

46. Huffington and Melissa.2020. Home Is Not A Safe Place for Everyone. 13 March 2020. https://www.huffingtonpost.co.uk/entry/domestic-violence

47. Melissa Godin.2020. As Cities Around the World Go on Lockdown, Victims of Domestic Violence Look for a Way Out. 18 March 2020. https://time.com/5803887/coronavirus-domestic-violence-victims/.

48. European Union Agency for Fundamental Rights. 2014. Violence against women: an EU- wide survey

49. Europol.2020. Pandemic profiteering-How criminal exploit the Covid-19 crisis, March 2020, Europol.

50. UNODC.2020. Coronavirus Disease (COVID-19) response-UNODC Thematic Brief on gender-based violence against women and girls; GBVAW_and_UNODC_in_COVID19_final_7Apr2020(1)

51. Davies SE, Bennett B. 2016. A gendered human rights analysis of Ebola and Zika: locating gender in global health emergencies. Int Aff ; 92: 1041-60.

52. Harman S.2016. Ebola, gender and conspicuously invisible women in global health governance. Third World Quart; 37: 52441.

53. Sochas L, Channon AA, Nam S.2017. Counting indirect crisis-related deaths in the context of a low-resilience health system: the case of maternal and neonatal health during the Ebola epidemic in Sierra Leone. Health Policy Plan; 32 (suppl 3): iii32-39.

54. Wenham C, Arevalo A, Coast E, et al.2019. Zika, abortion and health emergencies: a review of contemporary debates. Global Health; 15: 49.

55. Wenham C., Smith J., Morgan R. 2020. 'We are not aware of any gender analysis of the outbreak by global health institutions or governments in affected countries or in preparedness phases'.COVID-19: the gendered impacts of the outbreak. Source: https://www.thelancet.com/journals/lancet/article/PIIS01406736(20)30526-2/fulltext.

56. UN Population Fund (UNFPA).2020. “As COVID-19 Continues to Spread, Pregnant and Breastfeeding Women Advised to Take Precautions," UNFPA, March 5, 2020, https://www.unfpa.org/news/covid-19continues-spreadpregnant-and-breastfeeding women-advised-take-precautions.

57. Human Resources for Health (HRH).2020. Global Resource Center, "Resource Spotlight: Gender and Health Workforce Statistics, ” HRH, accessed March 14, 2020, https://www.hrhresourcecenter.org/gender stats.html.

58. UN High Commissioner for Refugees (UNHCR).2020. "UN Refugee Agency Steps Up COVID-19 Preparedness, Prevention and Response Measures," UNHCR, March 10, 2020https://www.unhcr.org/enus/news/press/2020/3/5e677f634/un-refugeeagency- steps-covid-19-preparedness-prevention-responsemeasures.html.

59. Center for Reproductive Rights.2017.Briefing Paper: Ensuring Sexual and Reproductive Health and Rights of Women and Girls Affected By Conflict https ://www. Reproductive rights.org/sites/crr.civicactions.net/files/documents/ga_bp_conflictncrisis_2017_07_25.pdf.

60. Peter Sands.2020. "COVID-19 Threatens the Poor and Marginalized More Than Anyone,” The Global Fund to Fight AIDS, Tuberculosis and Malaria, March 5, 2020, https://www.linkedin.com/pulse/covid-19threatens-poor-marginalized-morethan- anyone-peter-sands-1f/.

61. ILO.2016. Meeting of Experts on Violence against Women and Men in the World of Work Background paper for discussion at the Meeting of Experts on Violence against Women and Men in the World of Work (3-6 October 2016); Conditions of Work and Equality Department

62. Di Renzo GC, Giardina I,.2020. COVID-19 in Pregnancy: Consider Thromboembolic Disorders and Thromboprophylaxis, American Journal of Obstetrics and Gynecology, doi: https:// oi.org/10.1016/j.ajog.2020.04.017.

63. Sara E. and Davies, Belinda Bennett. A Gendered Human Rights Analysis of Ebola and Zika: Locating Gender in Global Health Emergencies, International Affairs, Volume 92, Issue 5, September 2016, Pages 1041-1060, https://doi.org/10.1111/1468-2346.12704.

64. Abrahams N, Devries K, Watts C, et al. Worldwide prevalence of non-partner sexual violence: a systematic review. Lancet 2014; 383: 1648-54.

65. IASC.2015.Guidelines for Integrating Gender-Based Violence Interventions in Humanitarian Action. Reducing Risk, Promoting Resilience and Aiding Recovery. 2015. https://gbvguidelines.org/wp/wp- 
content/uploads/2015/09/2015-IASC-Gender-based-Violence-Guidelines_lo-res.pdf.

66. Nidhi Kapur.2020. Gender Analysis: Prevention and Response to Ebola Virus Disease in the Democratic Republic of Congo. 31 January 2020. https:// relief web. int/ report/ democratic-republic-congo/genderanalysis-prevention-and-response-ebola-virus-disease.

67. Erika Fraser.2020. Impact of COVID-19 Pandemic on Violence against Women and Girls. 16 March 2020. http://www.s ddirect.org.uk/media/1881/vawg-helpdesk-284-COVID-19-and-vawg.pdf.

68. Diniz SG, Andrezzo HF.2017. Zika virus: the glamour of a new illness, the practical abandonment of the mothers, and new evidence on uncertain causality. Reprod Health Matters.25(49):21-25. DOI:10.1080/09688080.2017. 1397442

69. Gressick K, Gelpi A, Chanroo.2019. Zika and abortion in Brazilian newspapers: how a new outbreak revived an old debate on reproductive rights. Sexual Reprod Health Matters.;27 (2):20-23. DOI:10.1080/26410397.2019.1586818

70. Wong SF, Chow KM, Leung TN, et al.2004. Pregnancy and perinatal outcomes of women with severe acute respiratory syndrome. Am J Obstet Gynecol; 191(1):292-7.

71. Lam CM, Wong SF, Leung TN, et al.2004. A case-controlled study comparing clinical course and outcomes of pregnant and non-pregnant women with severe acute respiratory syndrome. BJOG; 111(8):771-4.

72. Alserehi Haleema., Ghassan Wali., Abeer Alshukairi., and Basem Alraddadi.2016. BMC Infectious Diseases (2016) 16:105; DOI 10.1186/s12879-016-1437-y

73. ILO.2020. COVID-19 and the world of work: Impact policy responses; ILO Monitor( 1st Edition); 18 March 2020

74. International Labour Organisation (ILO).2018. Care Work and Care Jobs for the Future of Decent Work: https:/www.ilo.org/wcmsp5/groups/public/---dgreports/---dcomm/--publ/documents/publication/wcms_633135.pdf.

75. EU. 2020. Coronavirus Pandemic In The Eu-Fundamental Rights Implications European Union Agency for Fundamental Rights fra-2020-coronavirus-pandemic-eu-bulletin 1_eng (1)

76. Jennifer L. Solotaroff and Rohini Prabha Pande. 2014.Violence against Women and Girls: Lessons from South Asia; South Asia Development Forum; International Bank for Reconstruction and Development / The World Bank

77. CARE. 2018.Women and Girls in Emergencies :https :// insights .care international .org .uk/media/k2/attachments/CARE_Women-and-girls-in-emergencies_2018.pdf.

78. Vintzileos WS, Muscat J, Hoffmann E, Vo D, John NS, Vertichio R, Vintzileos AM.2020. Screening all pregnant women admitted to Labor and Delivery for the virus responsible for COVID-19, American Journal of Obstetrics and Gynecology 2020, doi: https://doi.org/10.1016/ j.ajog.2020.04.024.

79. Duncan, Maru, World Economic Forum .2020. 'Coronavirus is coming for the world's poor. Here are six ways to help'.

80. Virginie Le Masson, Colette Benoudji, Sandra Sotelo Reyes, and Giselle Bernard. 2018. Violence against Women and Girls and Resilience Links, Impacts and Perspectives from the Chadian Context.

\section{Declarations}

\section{Abbreviations and Acronyms}

COVID-19; Novel Coronavirus Respiratory Disease-19 ;CDC: Centers for Disease Control and Prevention ; UNECA:UN Economic Commission for Africa; UNOCHA:UN Office for the Coordination of Humanitarian Affairs; GBV: Gender Based Violence; VAW/Violence against women/girls ; FGM/C: Female Genital Mutilation or Cutting; HTP: Harmful Traditional Practices; HIV/AIDS: Human Immune virus/Acquired immune Deficiency syndrome; UNHCR: UN High Commissioner for Refugees; RSV: Respiratory Syncytial Virus; PHEIC: Public Health Emergency of International Concern; MERS-CoV Middle East Respiratory SyndromeCorona virus (MERS-CoV); SARS-CoV: Severe Acute Respiratory Syndrome; ECDC: European Centre for Disease Prevention and Control; UNHROC: United Nations Human Rights Office of the Commissioner; UNODC; EU: European Union; ILO :International Labour Organization; SIDA: Swedish International Development Agency; SRH: sexual and Reproductive health; WHO: World Health Organizations; UN: United Nations; UNFPA: United Nations Fund for Population Agency; UNICEF: United Nations International Cultural and Educational Fund; USAID: United State Agency for International Development.

\section{Acknowledgements}

First of all, the author would like to acknowledge and give deepest thanks to Ms. Judy Price for helping in the editing of the manuscript. I would like to say thanks to my Friends and families for their support and showing affection at any time. 


\section{Funding}

N/A

\section{Availability of data and materials}

$\mathrm{N} / \mathrm{A}$

\section{Author Contributions}

EK is who conducted the selection of available studies for systematic review, drafted the first structure of the study, read and wrote based on the guidelines and the standards of the journals. Finally, all procedures and tasks throughout the development of the manuscript have been carried out by the author solely.

\section{Ethics approval and consent to participate}

Not applicable

\section{Consent for publication}

Not applicable

\section{Competing of interests}

The authors have declared, there is no conflict of interest regarding the concepts and methodological parts of the study.

\section{Authors Details}

Eyayu Kasseye Bayu is a Lecturer at the Department of Gender and Development Studies, College of Social Sciences and Humanities, University of Gondar, Gondar, Ethiopia. 